\title{
遠心ポンプ羽根車下流のディフューザ内変動流れに関する研究*
}

\author{
古川明 徳*1, 中川貴 博*2 \\ 高 原久定*1, 小野 祐 介 $^{* 3}$
}

\section{Study of Periodic Flow in Diffuser Downstream of Centrifugal Pump Impeller}

\author{
Akinori FURUKAWA*4, Takahiro NAKAGAWA, \\ Hisasada TAKAHARA and Yusuke ONO \\ ${ }^{* 4}$ Faculty of Engincering, Kyushu University, \\ 6 10 1 Hakozaki, Higashi ku, Fukuoka shi, Fukuoka, 8128581 Japan
}

\begin{abstract}
Periodic flows downstream of centrifugal pump impeller in vaneless and vaned diffusers were measured by using a single hole yawmeter with a phase locked sampling method. The flows were also calculated by a inviscid flow analysis with the blade surface singularity method. The periodic variations in calculated static pressure with impeller rotating quantitatively agree well with mea. sured ones. The flow behaviors in the vaned diffuser are discussed with measured and calculated results. The potential interaction between the impeller and diffuser blades appears more strongly than the impeller wake interaction. The appearance of static pressure fluctuations due to the impeller rotating in the fully vaned zone is different from that in the semi vaned zone of the diffuser. The existing of the peripheral surface of impeller outlet and the outlet edge of pressure surface of impeller blade causes the large pressure fluctuations in diffuser.
\end{abstract}

Key Words: Turbomachinery, Centrifugal Pump Impeller, Diffuser, Flow Measurement, Inviscid Flow Analysis, Pressure Fluctuation, Blade Rows Interaction

\section{1. まえ がき}

近年，各種産業用プラントの大形化に伴って高掦程 ディフューザポンプが多用され，また製造コスト削減 と設置スペースの制約からポンプの小形・高速化も進 み，単段当たりの高揚程化が要求される傾向にある。 ディフューザポンプの高性能・䯩揚程化には, 羽根車 下流において尼力回復を図るディフューザ内での流動 損失の低減が羽根車内における損失と闹様に重要とな る.さらに、これまで問題にされなかった羽根車翼と ディフューザ翼との動静翼干涉による振動問題も生じ ている，啩心ポンプディフューザ内の流れについて は，これまで，数多くの実験的研究(1)(2) や数值解析(3)(4) が行われているものの, ディフィーザ内流れおよび翼 列干渉に関して十分な理解が得られるまでには至って いない.

著者らは前報(5)において，羽根車翼形状を的確に考 慮することにより比較的簡便な非粘性計算でも，ポン

\footnotetext{
* 原稿受付 2001 年3月 26 月1.

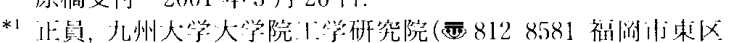
箱崎 $6 \cdot 10 \% 1$ ).

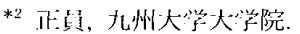

*3. 九州人等人院。

E-mail : fmfuru(a mech.kyushu u.ac.jp
}

プ羽根本「流の翼なしディフューザ内流れを議論し得 ることを示しな。そこで，この計算法を羽根車翼とデ イフューザ翼との一体流れ解析へと展開して遠心ポン プ妆根車下流の翼付きディフューザ内非粘性流計算を 行うとともに,ディフェーザ内流れの圧力と流速の実 験計測(6)を行った. 本論文では, 雨結果の比較から本 計算法の有用性を確認したうえで, 翼付きディフューザ内変動流れの様相を明らかにし, その変動流れに及 ぼす羽根車の回転位㯰と羽根車翼形状の影響について 考祭寸る.

\section{2. 実験装置および方法}

遠心ディフューザポンプを模した試験装㯰断面図を 図 1 に示寸. 水槽からの水は補助ポンプ・ベンチュリ 流量計を経て, 立軸駆動の壹心羽根車(1)抢よび平行壁 ディフューザ(2)へと流れ, 軸対称水路(3)でいったん自 由表面を形成して水槽へと戻る。自由表面水路の設徝 により，実機における瀜巻室の影響を除去し，羽根車 からの流出流が周方向にどこでも同じ風期的変動流れ となるように配慮した。供試羽根車扔よび翼付きディ フューザの形状を図 2 に示す、羽根車は流荲係数 $\phi_{2}=0.313$ で無任荷翼となるように設計され，入「1/ 出门径が $r_{1} / r_{2}=200 / 400 \mathrm{~mm}$, 翼高さ $b=30 \mathrm{~mm}$ の二 


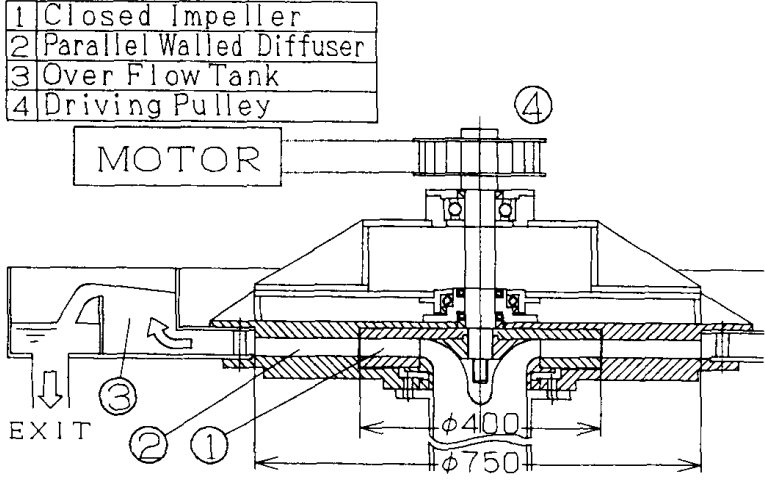

Fig. 1 Sectional view of pump equipment

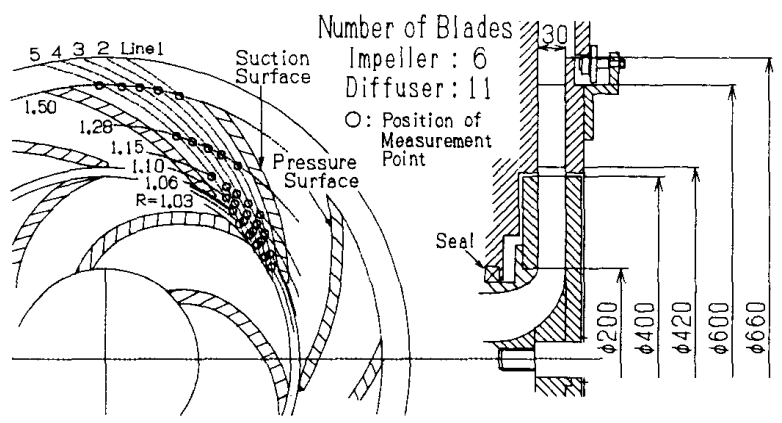

Fig. 2 Test impeller and vaned diffuser

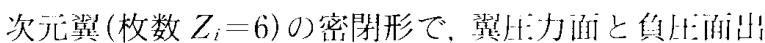

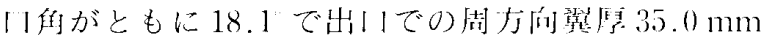

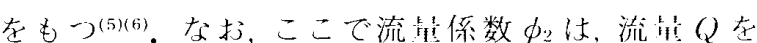

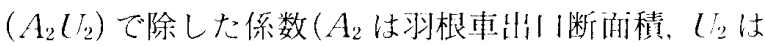
羽根車蚛门周速)である。岥根本吸込力バーラビリン ス部にはシールを付設して、妆根東側板とケーシング

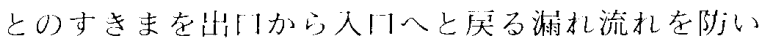
だ。ディフューザ翼は流最係数 $\phi_{d 2}=0.120$ に打いて

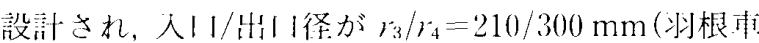
出门半径との比で $\left.R_{3} / R_{4}=1.05 / 1.50\right)$, 反り線上人1

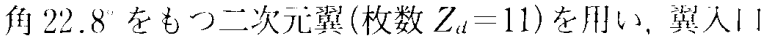

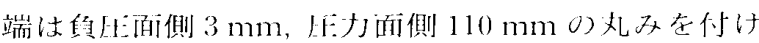

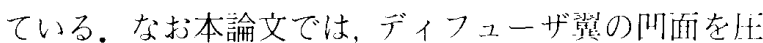

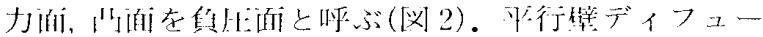

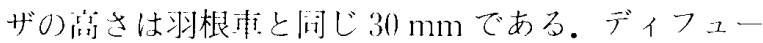

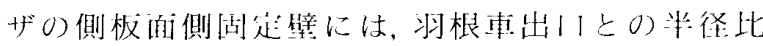
$R=1.03,1.06,1.10,1.15,1.28,1.50006$ 断面に ーメータ㨂人孔を設け，筫付きディフューザの布板消

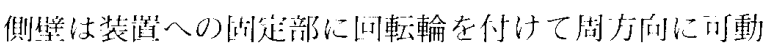

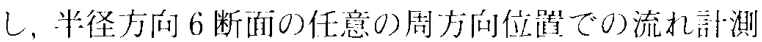

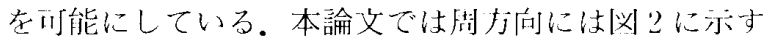

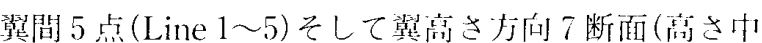

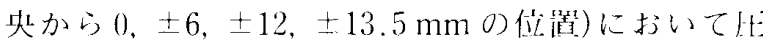
カセンサを組み込んだ単孔ヨーメータ(6)（取死部扩よ

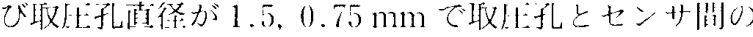

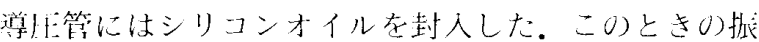
幅減衰と位相遅孔が現孔ない䦌波数限界は約 $1 \mathrm{kII \% )}$

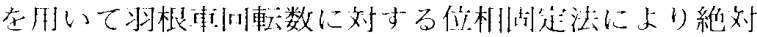

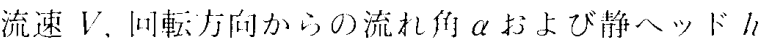

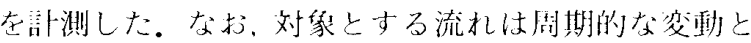

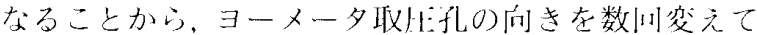
計测することにより多孔ヨーメータと间箱のデー夕が 取街できる゙。

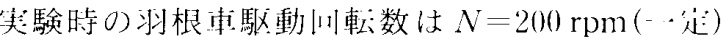
で、流れ計测は次のような若えで $\phi_{2}=0.146$ において 行った。遠心壮根車出门での流扎は，一般に，低流时 ほど後流域が明確に現れるも00，流速・旓へッドと もに出りト流直後で急速な一梯化をもたらす。一」。

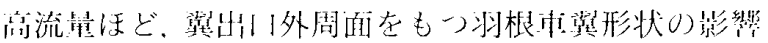

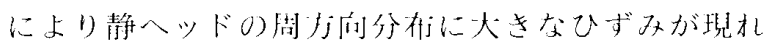

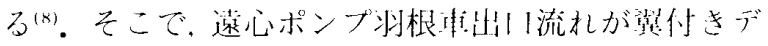

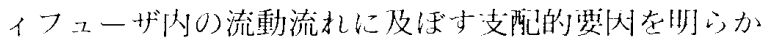
にすること在目的としている本論文では，整なしディ

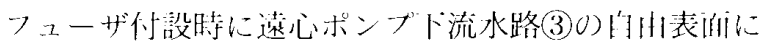
波( $\phi_{2}<$ 約0.1に扔いてディフューザ失速が発㤝) 在

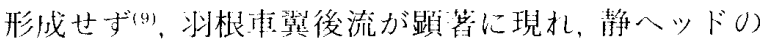

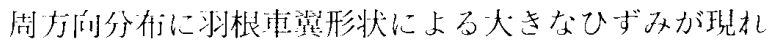

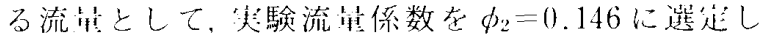

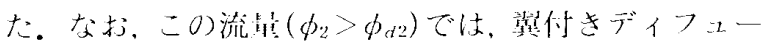

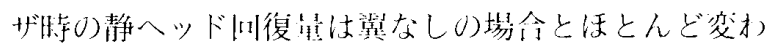

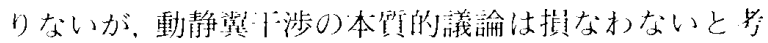
える。

\section{3. 非粘性計算法の概略}

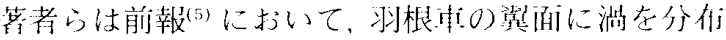

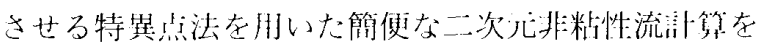
行い，翼なしディフューザ内流れしの挙動を考祭した。

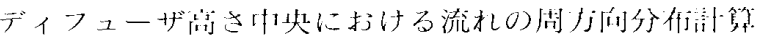
結果を実澌と比較して网 3 に拈揭する。ここで横軸 $\theta$

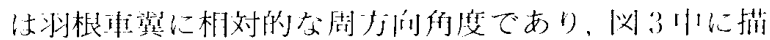

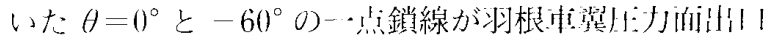

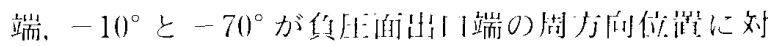
忠している。縦軸如はポンブ入口食へッド存基準と した静へッド、早籍を $\left[U_{2}^{2} /(2 q)\right]$ で除した係数である

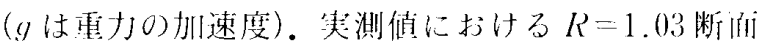

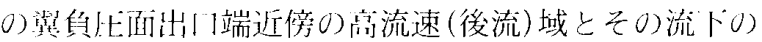

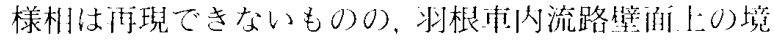

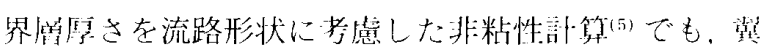

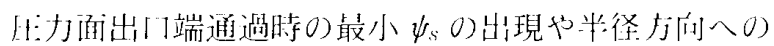
流トに伴って静へッドと流速が一様化寸る様子の傾[们 


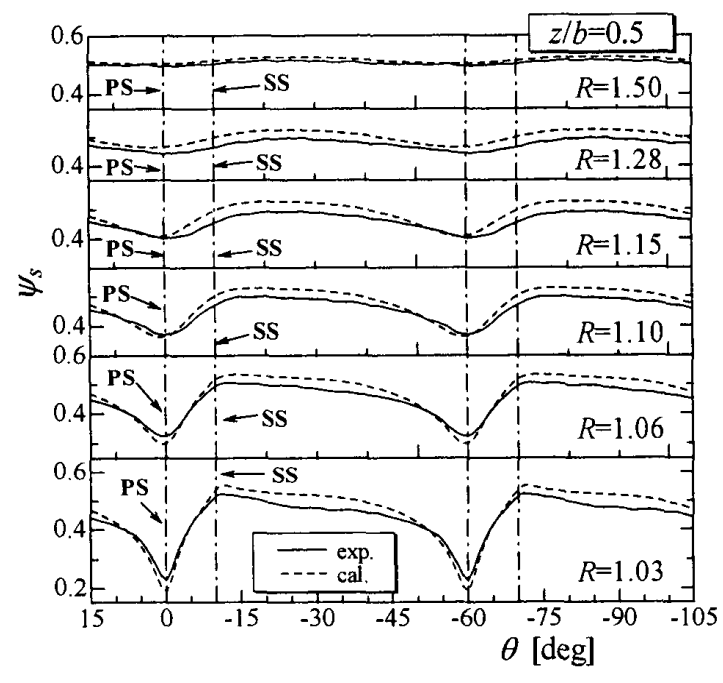

(a) Static head

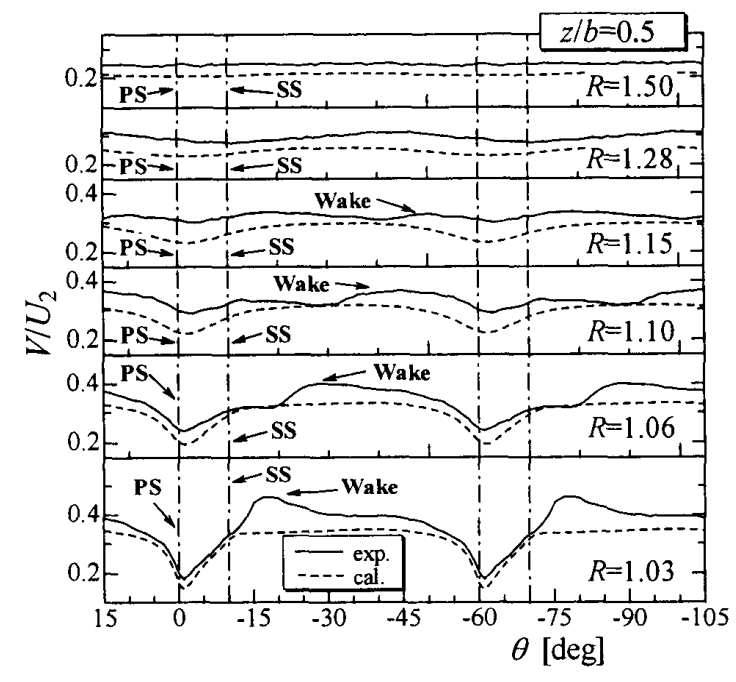

(b) Absolute velocity

Fig.:3 Circumferential distribution of static head and velocity in vaneless diffuser $(\phi=0.146)$

がとらえら扎てる。そこで本論文では，䩀付きデイ フューザの埸命に対して羽根䡉内とディフューザ筫列 内速情埸がー一体解析できるように，次の上うな搪張を 行った。

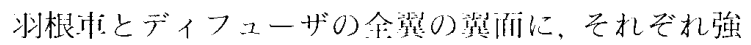
さ $\left.\iota_{n k i}, \mu_{\text {mkd }} O\right)$ 離散淌 $K_{i}, K_{d}$ 侗を分柿させ $(n=1$, $\left.\cdots, Z_{i}, m=1, \cdots, Z_{d t}, k i=1, \cdots, K_{i}, k d=1, \cdots, K_{d l}\right)$,

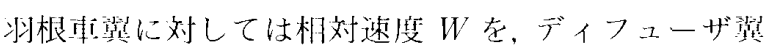
に対しては絶対速度 $V$ 存用いて流机が翼陌に㳂う条

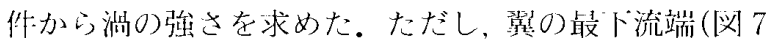

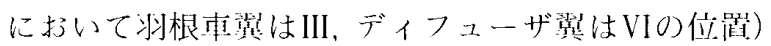
にはクッタの条件に二0 を課した。㳯算では，间転し

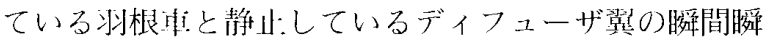

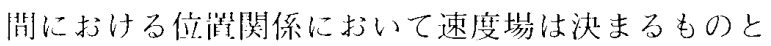

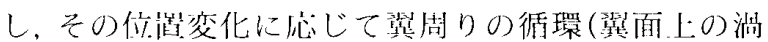
強さ）は変化するが，それに伴う翼からの淌放出は考 えていない，流れ場をより精度よく表すには，洞放山

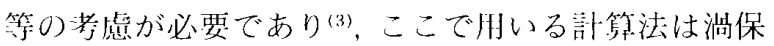
存則を無視している只で流体力学的にはやや疑間が残 るものの，部算の簡略化により，基付きディフューザ 内での流水変動を引き起こす壮根查翼形状とその出り 流れの基本的要网を容易に探ることができると判断 し、これを湖た。

また将根中内流れ棓算は、㹕なしディフューザで

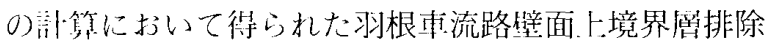
归さを考惫した流路形状をそのまま用いて行った。

特是点法により得られた速度埸からのディフューザ

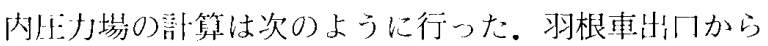
の絶対流れは秱期的変動流れとなるため, 絶対流れ場 に扔けるディフューザ筫列に流の静此座標点での全へ
ッドは時々刻々変化する。一方，ディフューザ琵列の

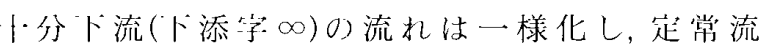
$(\partial \varphi / \partial t=0)$ とみなし得る。また，その断面での全へッ

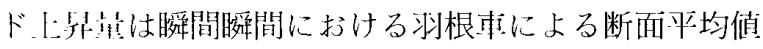
を保持する。したがって。これを式(ポンプ人に1全へ ッド其準)に表すと次のようになり，これよりディフ ユーザ内の静ヘッド $h$ を求めた。

$$
h_{\infty}+\frac{V_{\infty}^{2}}{2 g}=\frac{U_{2} V_{A 2}}{g}=\left(h+\frac{V^{2}}{2 g}+\frac{1}{g} \frac{\partial \varphi}{\partial t}\right) \cdots
$$

ここで $V_{0}$ は絶対速度の周分速度，tは時間で, 式中の 速度ポテンシャル $\varphi(t)$ は㣋根車とディフューザの全 琵に分析させた離散沾に対して次式から算出した。

$$
\begin{aligned}
& \varphi(t)=\frac{q}{2 \pi} \log r+\sum_{n=1}^{Z_{i}} \sum_{k i=1}^{K_{i}} \frac{\mu_{n k i}(t)}{2 \pi} \Delta \Theta_{n k i}(t) \Delta s_{n k i} \\
& \quad+\sum_{m=1}^{Z_{d}} \sum_{k d i=1}^{K_{d}} \frac{\mu_{n k d}(t)}{2 \pi} \Delta \Theta_{n k d}(t) \Delta s_{n k d} \cdots \cdots \cdots(2) \\
& \Delta \Theta_{l k^{*}}=\tan ^{-1} \frac{r \sin \theta-r_{l k^{*}} \sin \theta_{l k^{*}}}{r \cos \theta-r_{l k^{*}} \cos \theta_{l k^{*}}}+\cdots(3)
\end{aligned}
$$

ここで，qは単位高さ当たりの流量， $\Delta s$ は翼面渦分布 線上の線素堘, $(r, \theta)$ と $\left(r_{l k^{*}}, \theta_{l k^{*}}\right)$ は部算点抢よび 淌点の坐標で，その下添子なのlは $m$ または $n$ 、*は $i$ または $d$ を示す。

\section{4. 実測結果と計算結果との比較}

ディフューザ翼間流路内の Line 1，3，5 」:の測筀点 に打けるディフューザ珙高さ中央での静へッド 絶対速度 $V$ の時間変化について笑测値と計算値とを 比較して闵 4 に六す。ここで横軸の $t^{*}$ は時間を羽根 東翼通過周期 $T\left[=1 /\left(N Z_{i}\right)\right]$ で除した無次元時間であ り，測坔点がある翼間流路に対して妆根車翼(1)0)出口 外周面中央とディフューザ琶(2)の)削縁とが半径方向に 

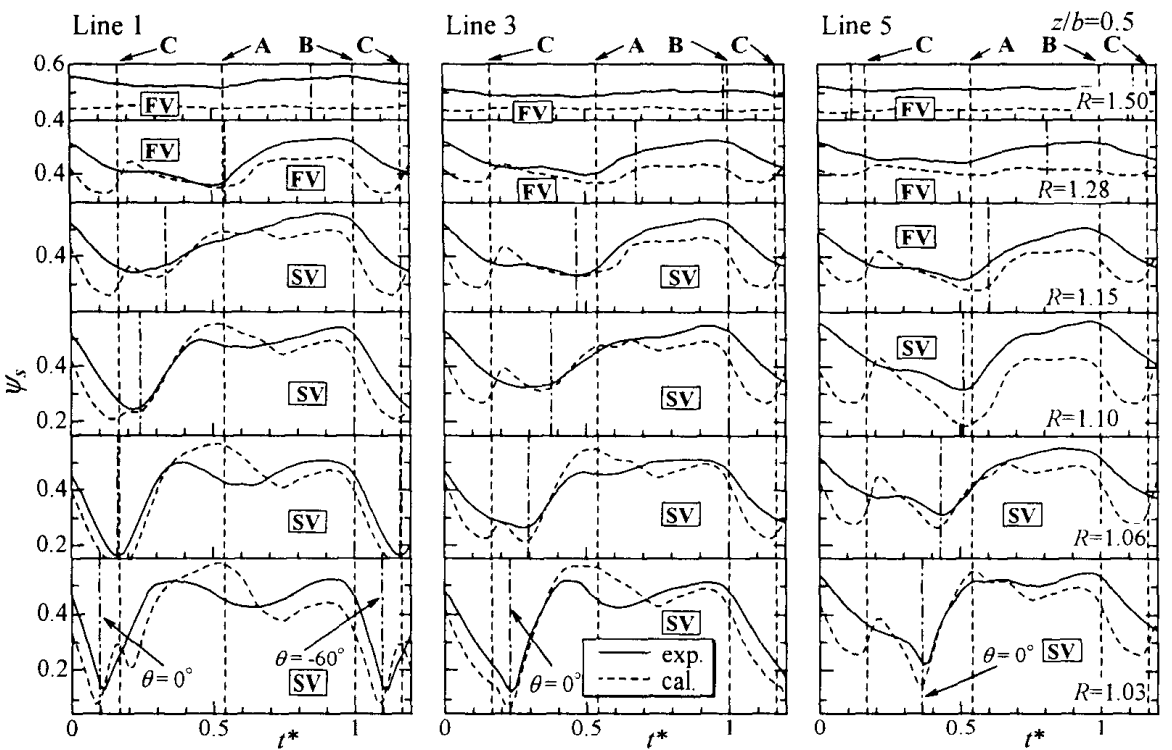

(a) Static head
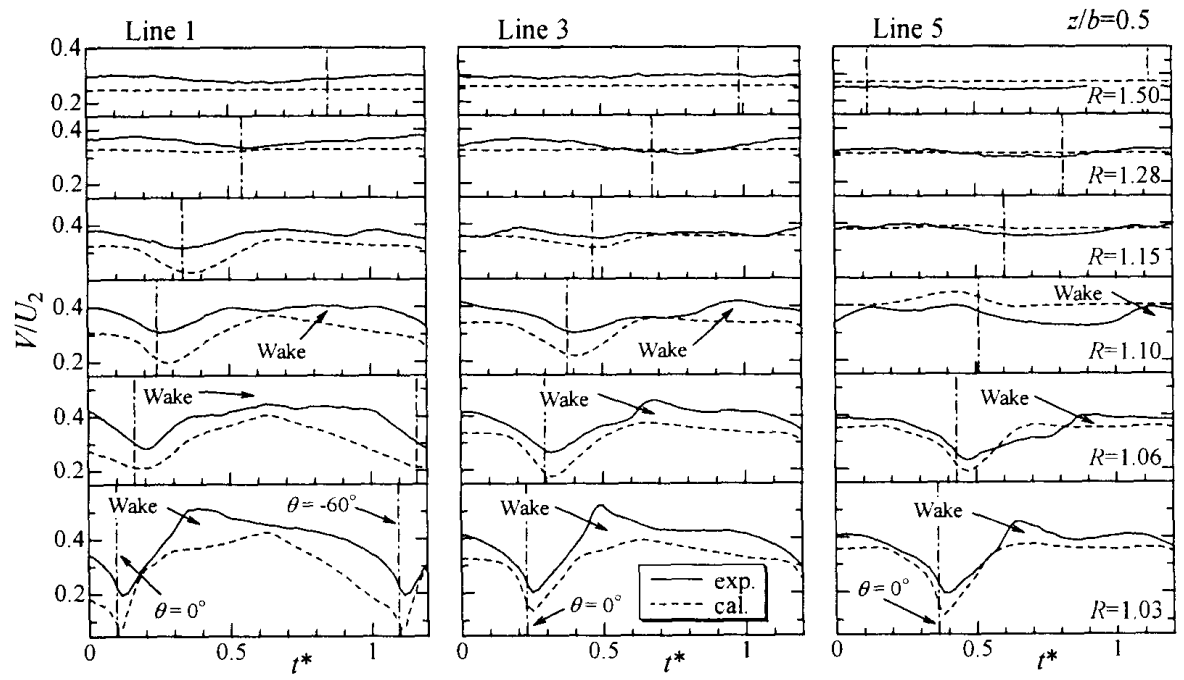

(b) Absolute relocity

Fig. 4 Comparison between measured and calculated results of flow fluctuations in vaned diffuser

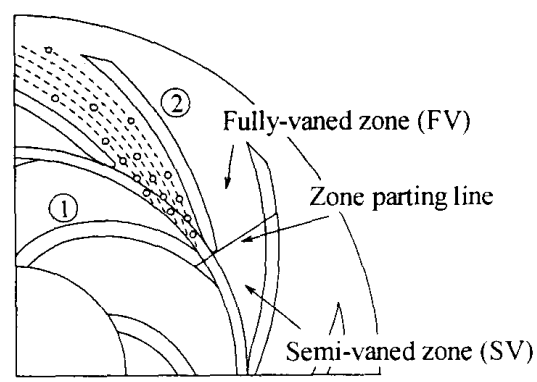

Fig. 5 Definition of $t^{*-0}$ and fully and semi raned \%ones

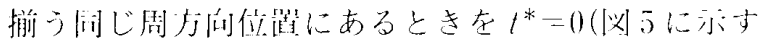

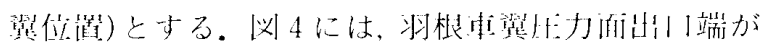

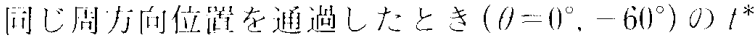

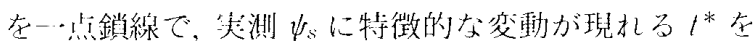

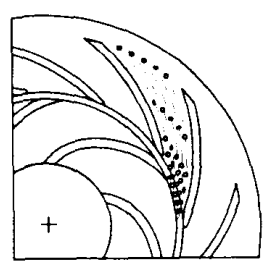

Time A

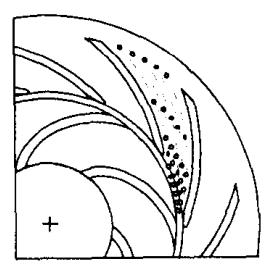

Time B

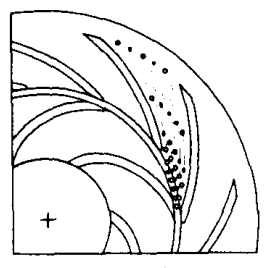

Time C
Fig. 6 Position of impeller and diffuser blades

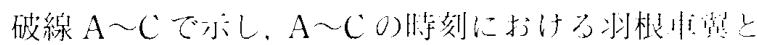

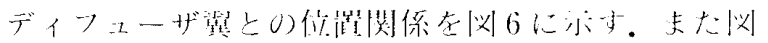

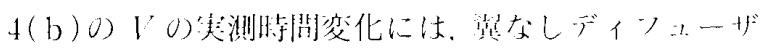

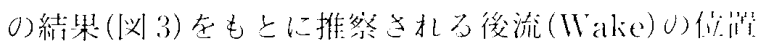

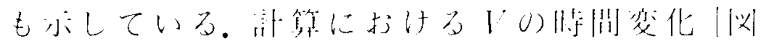

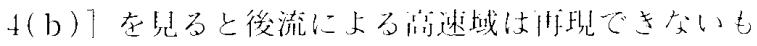


のの，隣接するディフューザ琵が半烽少问に重なる部 分の、流側 0 SV 域 (semi-vaned zone, 戍 5)では, ディフューザ琵前縁近傍(Line 5 で $R=1.10$ の测走

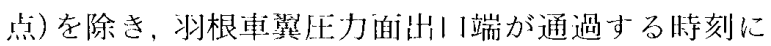
おいて低速となり，実測の変化と比較的よい一致を示 している。流路下流の FV 域 (fully vaned zone, Line 5 でR=1.150)測尘点扔よび $R \geqq 1.280$ )全测足点) では、Vの計算值は平たんとなるのに対し，実測では 後流抾散のためか若干の変動が残っている。

次に静へッドの時間変化 [図 $4(\mathrm{a})]$ を見ると, 四 3の翼なしディフューザに扔ける結果に比べ, 実测値

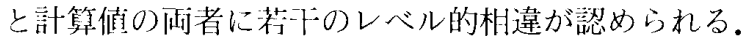
計算によると，羽根車の発生揚程は，ディフューザ翼 人りを猅根車出门から $R>1.20$ 位䈯まで哀ざけた場 全翼なしでの值(掦程係数 $\psi=0.558$ )とほぼ同じとな るが、ディフューザ翼入口を羽根車出门に近付けるに つれて低ドし，R=1.050位㯰にあるいまの場命， $\psi=0.512$ (時間平均㯰) となる。したがって闵 $4(\mathrm{a})$ に扔いて非粘性該算静へッドが英測值に比べて低くな った理由には，このときの計算揚程係数が低くなるこ と，そして掦程が低下するにもかかわらず刐根本流路

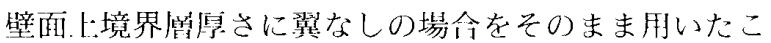
とにあると考えられる。しかしながら，計算と実測の 両結果に扔いても, 翼なしディフューザに比べて半径 比の大きい測定点まで大きな時間的変化が見られるこ と,そして，その変動はディフューザ翼負正面側 (Line 5)より无打面側(Line 1)0帕うが大きいことが 認められる。この䇥性的一致は, 羽根車出门流れが翼 付きディフューザ内の変動静ヘッドに及ぼす支配的要 因を探るには十分と考え，この計算結果をもとに考察 を進める、さらに細かく図を見れば，屾者の一致点と して, SV 域では羽根車珙生力面出口端の通過ととも

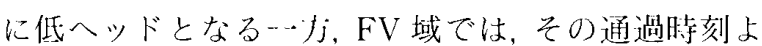

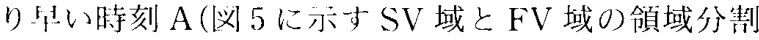
線上を羽根車㤹力面出门端が通過した)のとき低へッ ドとなること(6)，いずれの測是点に扔いても㭙刻 $\mathrm{B}$ 〜Cに扔いてへッドが急減すること，さらに，SV 域 0)測䇥点で $t^{*}=0.7$ (計算值，実测俌では $t^{*}=0.6$ ) 近 傍に扔いて田状の変化傾问を示すことが認められる。

戍 4(b)における $V$ 0実測值には，SV 域では，翼 なしディフューザ時と同様に, 非粘性計算結果との違 いとして後流域をとらえることができるもの0, FV 域に入ると明確な後流域は見られず，非粘性計算值と の顕著な違いは認められないこと，さらに図4（a）に 抢ける契測された 定性的にほ济括現できていることから考えて，翼付き ディフューザ内変動流れへの羽根車の影響は後流下渉 よりポテンシャルテ渉のほうが支配的といえる.

図 4 に扔いて，静へッド $\psi_{s}$ と速度 $V$ の時間変動を 比較すると将のほうが大きい。これは式（1）に扔け る有辺第 3 項(加速度項， $\partial \varphi / \partial t$ )によるものと考えら れる。そこでこの項が，式(2)からわかるように計算 に拀いて翼面に分布させた渦の強さに依存寸ることか ら，羽根車琶とディフューザ翼との位置変化に伴う淌 強さの変化を調べた。その洞強さ変動の振幅を、洞を 配置した点の半径とともに図 7 に示す。図 7 中に記し たギリシャ数字 $\mathrm{I} \sim \mathrm{VII}$ は図 7 右側の翼形状周りの位置 と対応している。眓 7 を見ると, 羽根車翼周りではIV 0)翼生力面出口端付近(ほほ負圧面出小端から出门外 周面全体抢よび划力面出口近傍の領域，この部分を領 域 Xと呼ぶ)において，一方，ディフューザ翼周りで は $\mathrm{V}$ を付した珙前縁付近(圧力面と貞王面の入门側両 面, 領域 Y)において渦強さ変動の振幅が大きいこと が知られる。そこで次に，羽根車翼の領域 Xおよび
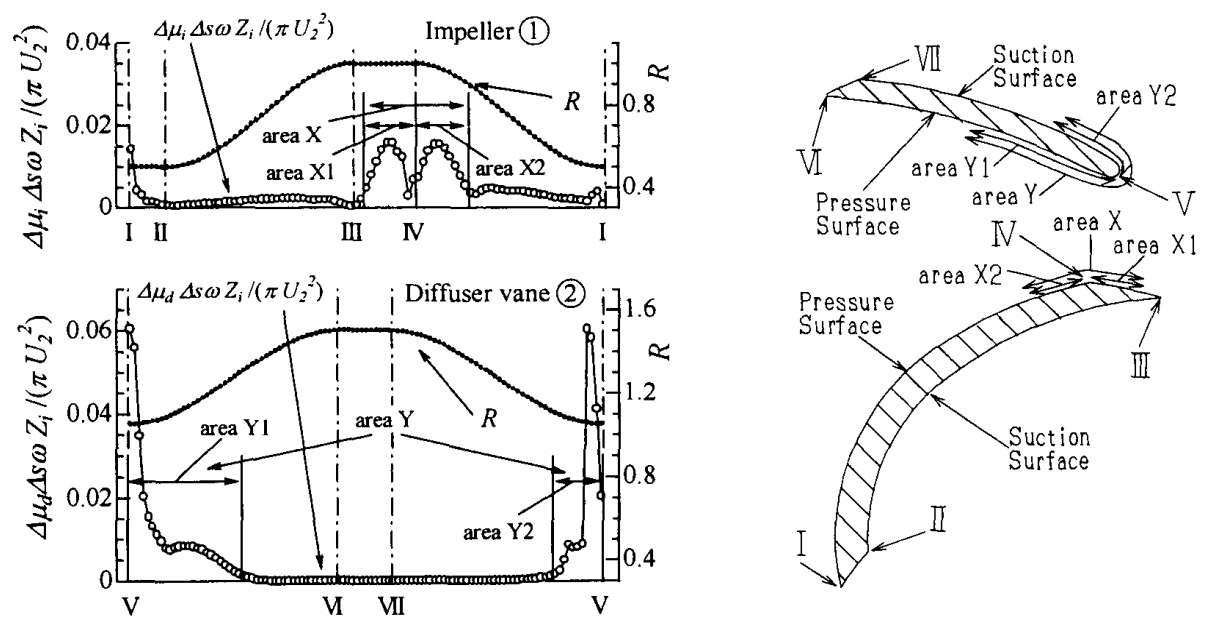

Fig. 7 Vortex strength fluctuation due to impeller and diffuser blades rows interaction 
ディフューザ琶の領域 Yに挹ける淌強さの変動が静

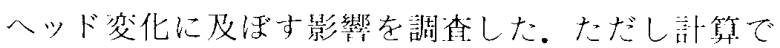

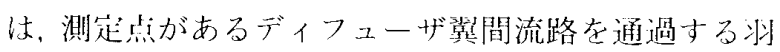
根拉琶 1 枚の領域 $\mathrm{X}$ を肞い，領域 $\mathrm{Y}$ は琵間流路を形

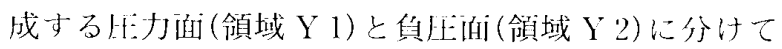

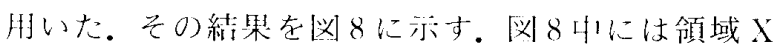
○)(笑線)，領域 $\mathrm{Y}$ の み(破線)、扔上び領域 $\mathrm{X}$ と領

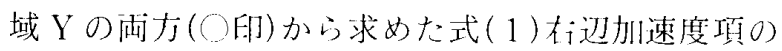

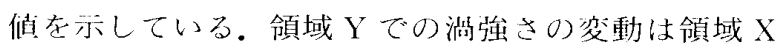
に比べて大きいにもかかわらず，艮8のすべての計算 点に扔いて領域 Y の影響は弱く、静ヘッド $\psi_{s}$ の変化
には領域 Xが支配的であることがおかる。威8を見

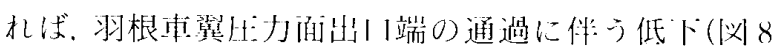

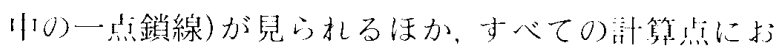

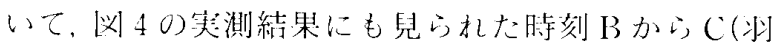

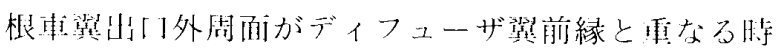
間)にかけて、如隇少する様子も現れている。また

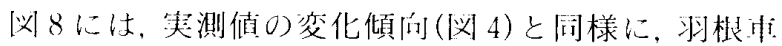

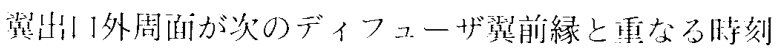
に界たるく の) 衿変化が涊められる。このことから，ポンプ刐根 †门瑟形状は通常，製作後の揚程調整が叮能なように
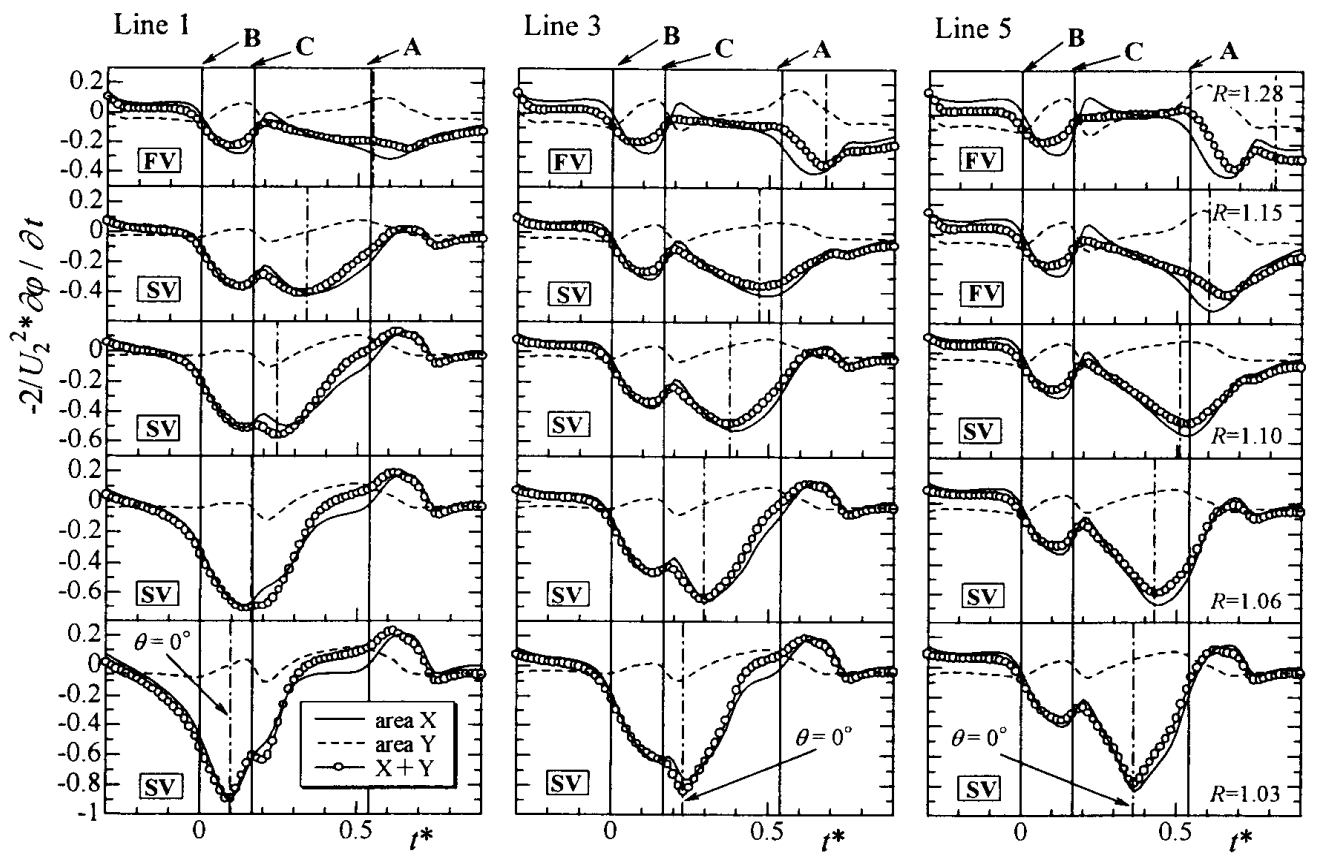

Fig. 8 Influence of change of vortex strengths in areas of $\mathrm{X}$ and $\mathrm{Y}$ on static head fluctuations
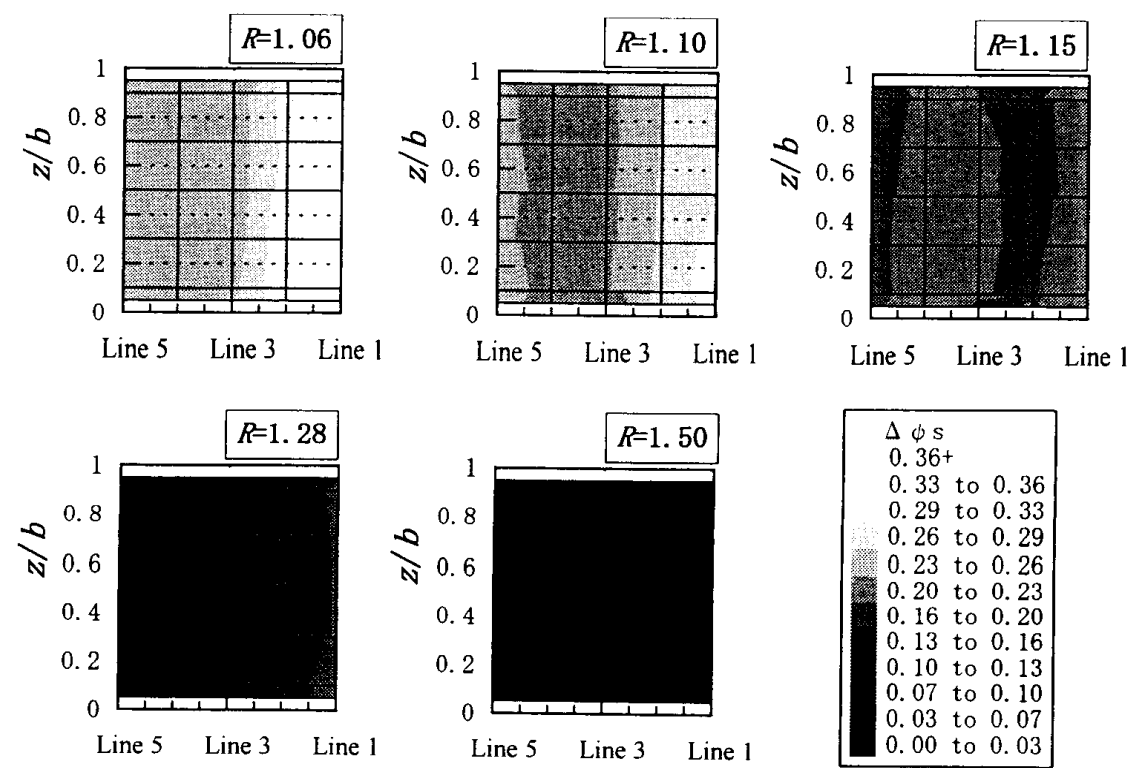

Fig. 9 Contours of measured $\Delta \psi_{s}$ in radial section 


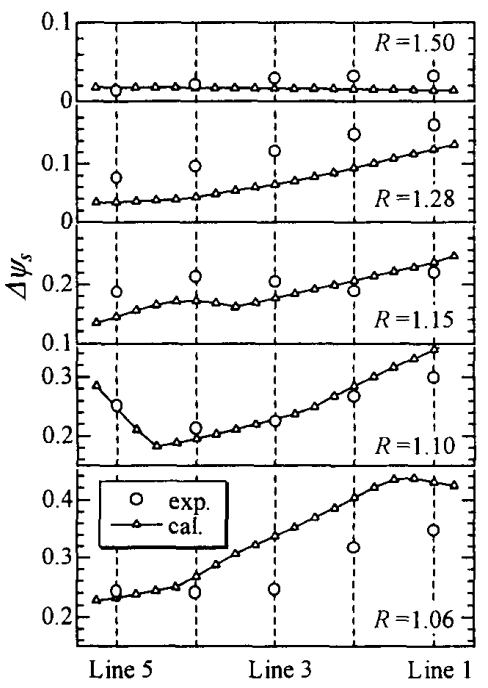

Fig. 10 Comparison between measured and calculated results of static pressure fluctuations

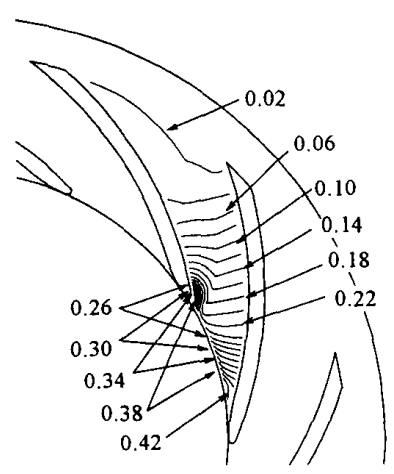

Fig. 11 Contours of calculated static pressure fluctuation in vaned diffuser

翼出门に外周面をもたせているが，この妆根車出い外 周面を付けることがディフューザポンプにおいてぬ の大きな変動をもたらしていることが知られる。

動静翼下涉により生じる庄力変動は非定常流体力と なり装置の振動や破壞をもたらすこともある。そこ で,ディフューザ翼間流路の測定点に扔ける静へッド 変動量 $\left(\Delta \psi_{s}=\psi_{s \max }-\psi_{s \min }\right)$ を求め, 図9に半径断面 での奏測 $\Delta \psi_{S}$ の珙間分布を，図 10 にディフューザ高 さ中央における $\Delta \psi_{s}$ の実測値と計算値の比較を, 図 11 に計算から求めた $\Delta \psi_{s}$ の翼間分布を示す。被 9 に 示寸実測 $\Delta \psi_{s}$ の珙間分布は翼宲さ方向にほぼ一様で あり二次元的となることが知られ，网 10 から計算結 果は笑测結果と同様の傾向を与えることがわかる，図 10 抢よび図 11 を見ると， $\Delta \psi_{s}$ の最も大きな領域はデ イフューザ翼圧力面入口側に存在し, それより小さい ものの $\Delta \psi_{s}$ が大きい領域が貟压面入口側にもまた存 在することが認められる。また，同一半径断面では翼
压力面 (Line 1) 側の変動量は大きいこと, そして流路 下流に進むにしたがって $\Delta \psi_{s}$ はさくなり，ディフ ューザ珙間流路出门である $R=1.50$ では压力変動は ほとんど零となることがわかる。

\section{5. 結言}

遠心ポンプ羽根車下流における翼付きディフューザ 内周期的変動流れを,ディフューザ失速や羽根車入 11・出いで逆流が生じていない高流量の点に扔いて計 测するとともに，翼形状を的確に考虑し得る翼面特異 点法による羽根車とディフューザ翼との非粘性流一体 解析を行って, 両結果を比較考察し, 次の諸点を得た。

（1）蘶心羽根車ト流のディフューザ内流れに現れ る羽根車の影響はポテンシャル正涉による圧力变動が 支配的である。

（2）羽根車とディフューザ翼の翼形状を考虑した 翼面特異点法による比較的簡便な非粘性計算でもディ フューザ内庄力変動は再現できる。

（3）揚程調整用に付ける遠心羽根車出凸外周面は ディフューザ内庄打変動を大きくする要因となる。

\section{文献}

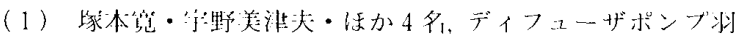

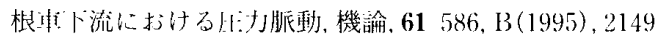
2156.

(2) Sinha, M. and Katz, J., The Onset and Development of Rotating Stall within a Centrifugal Pump with a Vaned Diffuser, Proc. Brd ASME/JSME Joint Fluid Eng. Conf.. FEDSM 997198 (1999), 17.

(3) Zhu, B. and Kamemoto, K., Simulation of The Unsteady Interraction of a Centrifugal Impeller with Its Iiffuser by an Advanced Vortex Method, Proc. Brd ASME/JSME Joint Fluid Eng. Conf., FEDSM 996821 (1999), 19.

(4) Shi. F. and Tsukamoto, II., Numerical Studies of Effects of Flow Rate and Radial (aap on Pressure Fluctuations Downstream of a Diffuser P'ump Impeller, Proc. 3rd ASME/JSME Joint Fluid Eng. Conf.. FEISSM 997341 (1999), 17.

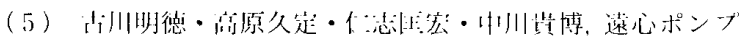

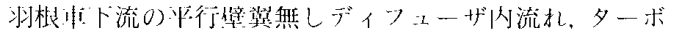
機械, 275 (1999), 307314.

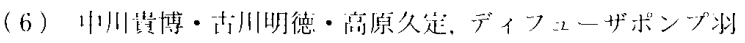

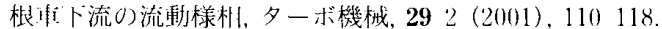

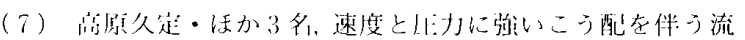

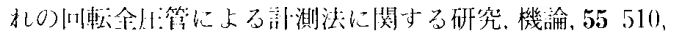
B (1989), 413 418.

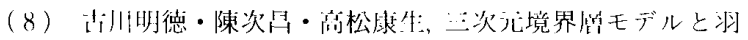

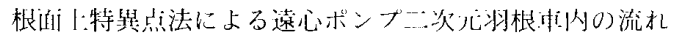

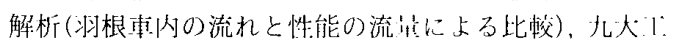
学柋報, 62 １ (1989), 49 55.

(9) Furukawa. A., Nakagawa, T. and Takahara, H., Downstream Flow of Centrifugal Pump Impeller in Vaneless Diffuser, Mem. Fac. Eng., Kyushu Univ., 60 $2(2000), 2133$. 